\title{
LITHIUM INTOXICATION IN COVID-19: A CASE REPORT
}

\author{
Melis Danışman Sonkurt \& Harun Olcay Sonkurt \\ A ̆grı Ĕ̆itim ve Araştırma Hastanesi, Psychiatry Clinic, Merkez, Ağrl, Turkey
}

received: 4.12.2020;

revised: 1.2.2021;

accepted: 27.2 .2021

$* * * * *$

\section{INTRODUCTION}

In December 2019, an outbreak of pneumonia of an unknown cause occurred in Wuhan, China. The virus, now named the acute respiratory syndrome corona virus-2 (SARS-CoV-2), has spread to whole world from Wuhan (Wang et al. 2020). While the virus mostly affects respiratory system, heart, kidneys, endothelium and central nervous system are also affected (Steardo \& Verkhratsky 2020). The knowledge regarding relationship between this disease's effects and psychiatric disorders and drugs is lacking. In this paper, a case of bipolar disorder who was hospitalized for COVID-19 and found to be intoxicated with lithium during hospitalization period is presented. It was aimed to address the common findings in COVID-19 and lithium intoxicity, the possible antiviral efficacy of lithium and the possibility of its use in COVID-19, the possible effects of drugs used in the treatment of COVID-19 on lithium toxicity, and the points to be considered in the treatment process. We obtained written consent from the patient before writing the case report.

\section{CASE}

A 64-year-old male patient with bipolar disorder was consultated to psychiatry from COVID-19 inpatient ward with disorientation. He was taking $600 \mathrm{mg} /$ day of lithium and was in remission for 5 years. In the examination, he wasn't cooperating, was distracted, disoriented, had a dysarthric speech and generalized tremor. His gait was ataxic.

Prior to admittance, he had hydroxychloroquine treatment for 5 days and was discharged with remission. After the discharge, he was hospitalized again because of diminished oral intake, disorientation, and tremor. Meropenem (3 grams/day) and favipiravir (1600 miligrams on Day 1, 600 miligrams in maintenance) treatments were started.

He was pre-diagnosed with lithium intoxication and tested for BUN, creatinine, electrolites and ECG. His lithium level was $2.28 \mathrm{mmol} / \mathrm{L}$, blood sodium was $128 \mathrm{mEq} / \mathrm{l}$. ECG was normal.

Lithium was stopped. It was recommended that the patient be followed up in the intensive care unit (ICU), the sodium level should be kept within normal range and appropriate fluid treatments be arranged. Quetiapine $25 \mathrm{mg} /$ day was started for his agitation and insomnia. After his delirium and intoxication clinic regressed after 5 days of ICU treatment, he was taken to the COVID-19 inpatient ward again. He was followed for 2 days in the ward, and he was discharged with good condition. He was re-evaluated on the first day and one week after discharge, no neuropsychiatric symptoms were present.

\section{DISCUSSION}

COVID-19 and lithium intoxication clinics are similar and may be perplexed. Despite lithium's potency, narrow therapeutic range and necessity to measure serum concentration regularly are among its particular disadvantages (McKnight et al. 2012). Toxicity symptoms include anorexia, nausea, weakness, and dizziness. These nonspecific symptoms are frequently encountered in the COVID-19 and this can make it difficult to diagnose patient with lithium intoxication.

\section{Joint effects of COVID-19 and lithium: Kidneys}

Acute kidney failure is one of the most important extra-respiratory problems in COVID-19, with higher rates in patients hospitalized in ICU (Lai et al. 2020). Lithium is eliminated by the kidneys. Therefore, impaired kidney function increases the risk of lithium toxicity (Ott et al. 2016). Glomerular filtration rate also decreases in long-term lithium users and renal failure is seen at a higher rate compared to the general population (Shine et al. 2015). In light of these; it was likely that the increase in serum lithium level started with decreased oral intake and dehydration. Later, as a result of the common nephrotoxic effects of SARS-CoV-2 and lithium, lithium excretion decreased. Hyponatremia also played a role as a facilitating factor in lithium toxicity in this process.

\section{Lithium as an antiviral drug}

Another remarkable circumstance in the case was that the PCR test was detected positive again, after a negative result, during the treatment process (see table 1). One of the reasons for the "false-negative" test result is that the viral RNA level is below the limit that the test can detect (Prinzi 2020). Many studies report that lithium inhibits viral replication (Murru et al. 2020). It's plausible that lithium may have contributed to the variability in PCR test results in the case. In his background, it was found out that the patient's oral intake was disrupted after his first discharge, therefore he remained dehydrated, and toxicity symptoms began. It's possible that the PCR test, which resulted as negative in Day 5, was 
Table 1. Important parameters during the follow-up

\begin{tabular}{|c|c|c|c|c|c|c|c|c|c|c|c|c|c|c|c|c|c|c|c|}
\hline Day & 1 & 2 & 3 & 4 & 5 & 6 & 7 & 8 & 9 & 10 & 11 & $12 *$ & 13 & 14 & 15 & 16 & 17 & 18 & 19 \\
\hline \multirow[t]{2}{*}{ State } & \multirow{2}{*}{\multicolumn{5}{|c|}{$1^{\text {st }}$ hospitalization }} & \multirow{2}{*}{\multicolumn{4}{|c|}{ Discharge }} & \multicolumn{10}{|c|}{$2^{\text {nd }}$ hospitalization } \\
\hline & & & & & & & & & & \multicolumn{3}{|c|}{$\begin{array}{l}\text { COVID-19 } \\
\text { inpatient ward }\end{array}$} & \multicolumn{5}{|c|}{ Intensive Care Unit } & $\begin{array}{r}\mathrm{CO} \\
\text { inpat }\end{array}$ & $\begin{array}{l}\text { D-19 } \\
\text { t ward }\end{array}$ \\
\hline PCR & + & & & & - & & & & & & & + & & & & & & & - \\
\hline Lithium level & & & & & & & & & & & & 2.28 & 1.68 & 1.23 & 0.62 & 0.21 & 0.07 & & \\
\hline
\end{tabular}

* The patient was consultated to psychiatry in the $12^{\text {th }}$ day, lithium treatment was stopped

performed in a period when blood lithium level was higher than the upper limit (see table 1). In his second hospitalization, after the cessation of lithium treatment even while he was taking favipiravir- PCR test became positive. The viral load in the patient seems to be affected by the lithium level, which seems to be reflected in the PCR result. This inference has raised our hopes for lithium's possible use in the treatment of COVID-19.

\section{COVID-19 Drugs and Lithium}

Unfortunately, there's no specific antiviral drug approved globally for COVID-19 yet. In the treatment, drugs with proven efficacy in other diseases are used and it's aimed to provide symptomatic treatment and supportive care (Provenzani \& Polidori 2020). Lithium and hydroxychloroquine do not have direct interactions, however there are warnings about increase in cardiac side effects (Anmella et al. 2020). Favipiravir also has no known interaction with lithium, and there are warnings regarding possible QT prolongation like hydroxychloroquine (Anmella et al. 2020). These data suggest that the COVID-19 drugs used in the case do not contribute to the lithium toxicity.

\section{CONCLUSION}

The COVID-19 pandemic has affected whole world. The unfamiliarity of many physicians involved in the treatment of COVID-19 with lithium treatment, and the limited knowledge of COVID-19 and the drugs used in its treatment may make it easier to miss the diagnosis of lithium toxicity, which can be mortal. Many factors such as renal dysfunction, dehydration, electrolyte imbalances, drug interactions, narrow therapeutic range of lithium may contribute to lithium intoxication in COVID19. Particular attention should be paid to dehydration in patients on COVID-19 treatment who are receiving lithium treatment, drug dose adjustments should be made by following up blood lithium levels frequently during COVID-19 treatment, and non-lithium treatment options should be considered, if possible, in patients with impaired renal functions.

\section{Correspondence:}

Harun Olcay Sonkurt, MD

Ağr Eğitim ve Araştırma Hastanesi, Psychiatry Clinic Firat Mh, Çınar Apt, B Blok, D: 21, Merkez, A $\breve{g r l}$, Turkey E-mail: hosonkurt@gmail.com

\section{Acknowledgements: None.}

Conflict of interest: None to declare.

\section{Contribution of individual authors:}

All authors reviewed and discussed the manuscript draft and contributed to the final manuscript.

All authors give final approval of the version to be submitted.

\section{References}

1. Anmella G, Arbelo N, Fico G, Murru A, Llach C, Madero $S$ et al.: COVID-19 inpatients with psychiatric disorders: real-world clinical recommendations from an expert team in consultation-liaison psychiatry. $J$ Aff Disorders 2020; 274:1062-67

2. Lai CC, Ko WC, Lee PI, Jean SS \& Hsueh PR: Extra-respiratory manifestations of COVID-19. Int J Antimicrobial Agents 2020; 56:106024

3. McKnight RF, Adida M, Budge K, Stockton S, Goodwin GM \& Geddes JR: Lithium toxicity profile: a systematic review and meta-analysis. The Lancet 2012; 379:721-728

4. Murru A, Manchia M, Hajek T, Nielsen RE, Rybakowski JK, Sani $G$ et al.: Lithium's antiviral effects: a potential drug for CoViD-19 disease? Int J Bipolar Disorders 2020; 8:1-9

5. Ott M, Stegmayr B, Renberg $E$ \& Werneke U: Lithium intoxication: incidence, clinical course and renal function - $a$ population-based retrospective cohort study. J of Psychopharmacology 2016; 30:1008-1019

6. Prinzi A: False Negatives and Reinfections: the Challenges of SARS-CoV-2 RT-PCR Testing 2020. Retrieved from https://asm.org/Articles/2020/April/False-Negatives-andReinfections-the-Challenges-of

7. Provenzani A \& Polidori P: Covid-19 and drug therapy, what we learned. Int J Clin Pharmacy 2020; 1:1

8. Shine B, McKnight RF, Leaver L \& Geddes JR: Long-term effects of lithium on renal, thyroid, and parathyroid function: a retrospective analysis of laboratory data. The Lancet $2015 ; 386: 461-468$

9. Steardo L \& Verkhratsky A: Psychiatric face of COVID-19. Trans Psychiatry 2020; 10:1-12

10. Wang C, Horby PW, Hayden FG \& Gao GF: A novel coronavirus outbreak of global health concern. The Lancet 2020; 395:470-473 